\title{
A Demoktesis de Robert Nozick
}

\section{Luiz Felipe Netto de Andrade e Silva Sahd (UFU)}

E-mail: felipesahd@yahoo.com.br

Resumo: o presente artigo tem como objetivo reconstruir argumentos centrais, desenvolvidos por Robert Nozick, acerca das posições extremas que não diferenciam Estado-providência e Estado totalitário na política dos libertarianos norte-americanos, isto é, sobre as afinidades percebidas por Nozick com as teses desta corrente de pensamento, embora se afastando num ponto essencial: a questão do Estado. Ao contrário da teoria anarquista, o Estado mínimo é preferível ao estado de natureza, tal como John Locke o descreve.

Palavras-chave: Estado mínimo, propriedade, liberalismo, direitos, teoria da titularidade.

\section{INTRODUĈ̣̃O}

A anti-utopia de Robert Nozick, filósofo americano falecido em 2002, é dirigida, antes de tudo, contra o Welfare State ou Estado do bem-estar social, coincidindo com sua crise nas sociedades democráticas ocidentais. Trata-se, porém, de uma objeção com características próprias, a saber: as argumentações política, jurídica e econômica são traduzidas em termos éticos nas teorias das vinculações morais. O libertarianismo de Nozick, portanto, propõe-se difundir e renovar o pensamento 
liberal clássico, apoiando-se na filosofia de John Locke. É uma filosofia ética com incidências políticas que, colocando o problema das relações entre a liberdade e o poder, resolve-o por uma defesa vigorosa da esfera privada e de sua autonomia ante os assaltos da autoridade pública. A comunicação pretende abordar o que Nozick chama de demoktesis, isto é, a legitimidade da democracia como procedimento de deliberação coletiva, direta ou representativa, que decide por maioria - absoluta ou simples - sobre as questões que afetam a todos os cidadãos. Nozick vê-se obrigado, por razões de coerência, a concluir que a democracia é eticamente legítima se, e somente se, é precedida de demoktesis.

Nozick começa afirmando que os indivíduos têm direitos e que há coisas que nenhuma pessoa ou grupo pode fazerlhes sem violar esses direitos. Esses direitos, que em Anarquia, Estado e Utopia "são apenas sugeridos através de algumas menções ao imperativo categórico kantiano, são justificados em Explicações Filosóficas”, onde se apresentam argumentos para mostrar que um ser humano é valioso e que por isso merece ser respeitado.

Para Nozick, "valioso" é aquilo que consegue conciliar a diversidade na totalidade, sem que, no entanto, cada um dos elementos seja descaracterizado. Cada ser humano, assim, é um ente "sagrado", cujo valor consiste não em cada um dos átomos que o compõem, mas sim na harmonização dos mesmos, que é única. Esta harmonização, em si mesmo valiosa, adquire "sentido" ao vincular-se, como uma contribuição, a uma entidade mais ampla. O homem, que é ele mesmo a unidade de uma diversidade e que por isso "tem valor", adquire "sentido" ao formar parte de uma sociedade que não eliminará sua unidade, mas sim o incorporará em uma nova diversidade harmoniosa.

O homem, enquanto ser valioso, pode dar sentido à sua vida, contribuindo e originando valor, "merecendo" assim ser respeitado. Seus direitos, pois, não devem ser violados. Quais 
seriam, porém, esses direitos? Nozick evita dar uma resposta taxativa a esta interrogação e ensaia um caminho que, ao final, se revelará problemático. Para ele, os direitos de outrem determinam as restrições de nossas ações. Mais exatamente, o valor do outro acaba por impor-me restrições não ao meu valor que não é comparável, por ser incomensurável -, mas à minha liberdade de atuar.

As "restrições morais indiretas" estabelecidas pelos merecimentos de cada indivíduo não nos dizem o que devemos fazer, mas aquilo que não devemos fazer, a saber: não matar, não violar propriedade alheia; trata-se, então, mais propriamente de "deveres" e não de "direitos", e a diferença aqui não é pequena. O problema, porém, é que se aceitarmos que os indivíduos são seres sociais, deveríamos aceitar também que a liberdade não pode ser entendida só em termos negativos. Se nossa realização como seres humanos está assentada na premissa de que devemos ser valorizados por nossa unidade formar parte de uma diversidade que não nos negue, o outro não é só o limite à minha liberdade, mas também a condição de possibilidade da mesma. Nozick parece não só não ter isto em conta, como também chega a equiparar liberdade com o uso discricionário da propriedade.

Contudo, se tomarmos a sério que a liberdade é ausência de coerção, então poderíamos considerar a possibilidade de "medir" nossa liberdade de acordo com aquilo que somos capazes de realizar (ou de nos abster de realizar) seguindo nossa própria vontade, que em Nozick aparece como um dado meramente subjetivo, afastado da sociedade. Deste modo, se outros homens e o que lhes pertence legitimamente são nossos limites morais, uma pessoa será mais livre quanto mais possua. Em outras palavras, a distribuição de bens é, ao cabo, uma distribuição de liberdade.

Considerando esta lógica, esperar-se-ia que, dado que todos os homens em princípio merecem sua liberdade, Nozick apoiasse algum tipo de redistribuição de bens, ao menos no es- 
tilo do Rawls. Entretanto, Nozick faz exatamente o contrário, rejeitando não só a posição de Rawls, mas também o conceito mesmo de distribuição, por entendê-lo coercitivo, negador de nossa dignidade. Nenhuma pessoa ou grupo de pessoas pode dizer-nos o que devemos fazer nem tampouco obrigar-nos a ser melhores ou a ajudar a nossos congêneres, afirma Nozick. Mas, no sentido de Nozick, acaso não é coercitiva toda situação social ou política? Não se trata tudo isto de uma "robinsonada", como gostava de dizer o velho Marx? Nozick trata de demonstrar que não. Eis a tese central de Nozick:

Nossa principal conclusão é que o Estado mínimo, limitado às funções retritas de proteção contra a força, o roubo, a fraude, de fiscalização do cumprimento de contratos e assim por diante, justifica-se; que o Estado mais amplo violará os direitos das pessoas de não serem forçadas a fazer certas coisas, e que não se justifica; e que o Estado mínimo é tanto inspirador quanto certo. Duas implicações dignas de nota são que o Estado não pode usar sua máquina coercitiva para obrigar cidadãos a ajudarem a outros ou para proibir atividades a pessoas que desejam realizálas para seu próprio bem ou proteção. (NOZICK, 1991, p. 9)

Para justificar sua hipótese de Estado "spenceriano", Nozick inicia um percurso que tem início no estado de natureza lockeano. Entretanto, em vez de limitar-se a enumerar os inconvenientes do estado natural, pelos quais Locke acredita que se faz necessário passar à sociedade civil, Nozick expõe a possível resolução dos problemas sem necessidade de originar um governo. Dessa forma, oferece-nos o que ele chama "de mão invisível": "uma explicação de mão invisível mostra que o que parece ser um produto do trabalho intencional de alguém não foi produzido pela intenção de ninguém" (NOZICK, 1991, p. 34). O Estado, aqui, nasce do estado de natureza segundo um arranjo não coordenado de ações singulares e de indivíduos racionais, enquanto a respectiva teoria da legitimação, uma explicação através da invisible hand, representa uma legitimação não 
intencional que renuncia a um acordo expresso. Ao contrário dos filósofos modernos que defendiam a ruptura manifestada no contrato originário, Nozick insiste na continuidade do processo que faz do Estado mínimo um Estado privado. Vejamos uma pouco as implicações problemáticas da argumentação nozickeana.

No prefácio de Anarquia, Estado e Utopia, Nozick reconhece que a sua pretensão não ultrapassa a uma mera "exploração filosófica do tema”, feita com sinceridade e para o leitor, sem ocultar-lhe os problemas. É consciente de que seu livro é um ensaio, isto é, "não apresenta uma teoria precisa da base moral dos direitos individuais; tão pouco contém o estatuto preciso nem a justificação da teoria tripartida da justiça distributiva". Essa tarefa, alerta o autor, seria realizada num futuro próximo; infelizmente, não realizou o prometido, talvez porque, como aqui mesmo pressagia, "o resultado seria diferente e exigiria modificações na superestrutura aqui levantada" (NOZICK, 1991, p. XIV). A questão, portanto, é se o ensaio mantém a coragem do enfoque com um mínimo de consistência. A primeira parte, porém, é a única que segue rigorosamente uma metodologia construtivista. Com o título "Teoria do estado de natureza ou como recair no Estado sem realmente tentar", o interesse da construção que o autor propõe elaborar justificaria a renovação de um conceito tão "arcaico" como o de estado de natureza. Trata-se, assim, de uma construção com propósitos "explicativos" da esfera política. Nozick assinala três possíveis "modos de entender a esfera política: 1) explicá-la inteiramente em termos do não-político; 2) considerá-la como emergindo do não-político, mas irredutível a ele, um modo de organização de fatores não-políticos compreensível apenas em termos de novos princípios políticos; ou, 3) encará-la como esfera inteiramente autônoma" (NOZICK, 1991, p. 21). Nozick opta pelo primeiro modo por ser o que "promete uma compreensão plena de toda a esfera política”, o que a converte na "alternativa teórica mais desejável, a ser abandonada apenas 
no caso em que se mostre impossível” (NOZICK, 1991, p. 21). Propõe, por isso, denominá-la a "explicação fundamental". Para desenvolver a sua construção, Nozick adota a estratégia da "explicação potencial”, garantida pela autoridade epistemológica de seu mestre Hempel, que consiste essencialmente na tese segundo a qual "uma explicação será correta se tudo que nela se menciona mostra-se verdadeiro e completo”. Em todo caso, uma "explicação potencial fundamental oferece uma importante explicação até mesmo quando não é a explicação correta”. Desse modo, Nozick adota para a sua construção o conceito lockeano de estado de natureza.

$\mathrm{Na}$ realidade, Nozick se limita a subscrever as principais teses da construção lockeana da inviolabilidade dos direitos naturais dos indivíduos; posteriormente, e num segundo plano, reconstrói os "inconvenientes do estado de natureza" mediante os quais o próprio Locke adianta que "é o governo civil o remédio apropriado" (NOZICK, 1991, p. 26). Obviamente, não posso seguir aqui em detalhes a reconstrução que faz Nozick de tais inconvenientes e sua recondução, por meio de processos de tipo "mão invisível”, até o Estado mínimo, que ocupa, como já disse, toda a primeira parte, limito-me apenas em elaborar um resumo crítico. Do ponto de vista epistemológico, o pouco que se pode dizer da construção nozickeana é que permanece confusa. Ao adotar a primeira das três opções possíveis, Nozick opta por um enfoque inteiramente ético da dimensão política. Isso implica que o critério moral não somente é decisivo para julgar a situação do governo civil sobre os indivíduos, mas que é também o único critério relevante. $\mathrm{O}$ critério moral que rege as relações entre os indivíduos (o respeito aos direitos legítimos de cada indivíduo) é o único que permite ajuizar a atuação do Estado sobre os cidadãos; qualquer atuação que leve em consideração outro critério é de antemão "imoral”. Este posicionamento inicial de Nozick, porém, mais prejulga do que resolve o problema da justiça, uma vez que nem sequer invoca algumas convicções morais espontâneas que justificaram o pró- 
prio ponto de partida. Ainda assim, Nozick adota a primeira das opções, a redução do político ao não-político. A opção é, em tese, a mais arriscada das três, embora pareça a mais promissora, por isso o autor deveria proceder a elaboração de uma cuidadosa fundamentação da mesma; em lugar disso, Nozick não só a assume, mas também procede na identificação injustificada do não-político com o privado, o que de modo algum resulta óbvio, pois a tradição do contrato social, em especial a de Jean-Jacques Rousseau, situa as bases do poder estatal no pacto ou acordo público dos indivíduos. E não basta que Nozick apele para o fato natural das "existências separadas", pois mesmo aceitando a sua condição de fato natural, isso não implica que se trata do direito natural primário, como dá a entender o autor, pois o fato cultural-social é igualmente primário no homem. O enfoque de Nozick, em compensação, toma por suposto que tal dimensão cultural-social carece de relevância, o que não só é demasiado arbitrário, mas também prejulga a solução do problema, reduzindo-o a um enfrentamento entre o indivíduo privado inocente e o Estado avassalador.

$\mathrm{Na}$ construção do Estado mínimo, porém, o Estado surge como um resultado não desejado, mas inevitável, de processos de tipo "mão invisível", isto é, das associações ou "agências de proteção" dos direitos morais que os próprios indivíduos promovem, passa-se, seguindo uma motivação egoísta e racional, a "agências de proteção dominante" e ao minimal state. Está claro que a pretensão de Nozick, ao ajustar a sua construção à estratégia da "explicação potencial", é de oferecer um modelo normativo do Estado moralmente aceitável, independentemente da realidade factual e de sua viabilidade. Mas uma vez que a construção parte de premissas exclusivamente morais e privadas, Nozick não pode pretender que o Estado mínimo seja realmente um Estado, por mais restrito que ele seja, a não ser como modelo moral aceitável do ponto de vista privado para julgar a atuação do próprio Estado. De fato, a "explicação potencial” é uma construção lógica e, por isso, não pode oferecer 
um modelo de Estado, apenas um modelo moral e privado de Estado, segundo as premissas de sua construção. A descrição dos vários e sucessivos passos - sempre segundo o modelo de tipo "mão invisível" - que legitimam as agências protetoras dos direitos da mônada moral, que é o indivíduo (por mera divisão do trabalho e especialização), à agência dominante e ao Estado mínimo, é pouco convincente. Ela evita a todo custo introduzir a figura do contrato social originário, pois este ofereceria uma base legitimadora do Estado muito mais ampla e, sobretudo, distinta, que as vinculações morais individuais. Nozick justifica a exclusão do pacto porque o levaria à uma dimensão teleológica que sua "explicação potencial fundamental" exclui por princípio; além disso, a noção de Estado permite superar o problema de redistribuição: a agência dominante prestaria os seus serviços inclusive a quem não pagasse por eles, ou mesmo pagasse menos, para proteger melhor a seus associados. De modo que, sem pretendê-lo, por um processo de tipo "mão invisível”, chega-se obrigatoriamente ao Estado mínimo.

Em última instância, sem um pacto social, mesmo implícito, Nozick não pode justificar suficientemente o Estado mínimo ou "Estado sereno", reduzido a proteger os "direitos lockeanos" dos indivíduos. Tampouco parece que o minimal state resolve o problema de redistribuição, pois o Estado mínimo realiza uma política com tais características por razões funcionais e não por razões de justiça. Sem o pacto, Nozick se vê obrigado a introduzir uma distinção confusa e demasiado ad hoc. E o que é o mais grave, além disso, não evitaria tratar os indivíduos como meios (através de processos compensatórios) e contra o imperativo categórico kantiano a que Nozick apela (imperativo que na teoria kantiana supõe o pacto social).

Consideremos agora a Teoria da Titularidade e suas implicações à noção de Estado democrático. A visão dos direitos do indivíduo à vida e à liberdade harmoniza-se bem com a intuição anarquista, segundo a qual cada pessoa tem direito ao autogoverno. Não obstante, apesar do título do livro de No- 
zick, o autor não compartilha a máxima proferida pelo socialista francês Pierre Proudhon, "a propriedade é um roubo". Nozick não aceita esta opinião, proclamando que, justamente com os direitos à vida e à liberdade, os indivíduos podem vir a ter direitos à propriedade. Estes direitos entrarão também na "esfera protegida" do indivíduo, pois, se legítimos, serão tão invioláveis e abrangentes quanto, por exemplo, os direitos aos órgãos (Cf. NOZICK, 1991, p. 206). Ninguém pode interferir na propriedade do indivíduo sem o seu consentimento, mesmo em favor de um bem maior. Quando as pessoas têm, porém, direitos à propriedade? Qual o fundamento da aquisição da propriedade privada moralmente justificada? Se alguns pensam que a propriedade deveria ser distribuída com base na necessidade, se outros crêem que ela deva ser repartida entre aqueles que a merecem, Nozick tem uma visão diferente. Considerações de titularidade, não de mérito ou necessidade, deveriam ser decisivas na aquisição da propriedade individual. Mas o que Nozick entende por titularidade? Utilizando-se de uma situação hipotética, propõe ao leitor uma situação plausível: suponhamos uma pessoa muito rica que acabou de receber inesperadamente uma herança; certamente ela não necessita da fortuna recém-adquirida, talvez nem mesmo tenha feito muito esforço para merecê-la, ainda assim, apesar da opinião sobre a necessidade ou o mérito da aquisição, somos inclinados a dizer que a herança é sua por direito, isto é, que o herdeiro está autorizado, habilitado a ela. É nesta teoria da titularidade da justiça (Entitlement Theory of Justice) que Nozick se detém. Em outras palavras, não são as características da pessoa que devem ser decisivas à justiça das posses, mas como foi obtida tal propriedade, se de modo autorizado, habilitado ou não.

São dois os procedimentos apresentados por Nozick que habilitam as pessoas à propriedade. Ela pode ser adquirida através de uma "transferência" entre indivíduos por meio de uma transação voluntária, ou "apropriada" da natureza, se não pertencer a ninguém, desde que o bem-estar dos outros não 
seja diminuído por isso. Este último, porém, contém uma cláusula restritiva, conhecida por cláusula lockiana (lockean proviso), que impede que a Terra e seus recursos naturais se reduzam a um vasto self-service gratuito em que o primeiro a chegar é também o primeiro a ser servido. Acrescido de um terceiro princípio, o da "retificação", que determina a maneira como devem ser corrigidos os desvios em relação aos direitos de apropriação original e de transferência, Nozick opõe-se a "teorias padronizadas" da justiça que estipulam a distribuição de riqueza ou receita conforme as características das pessoas, como "as menos favorecidas" de Rawls. Uma teoria de Estado com finalidade, afirma Nozick, tal como a que Rawls caracterizou, será constantemente perturbada pelas ações livres, e não de todo injustas, dos indivíduos e induzirá à interferência constante na vida desses indivíduos. Os direitos garantidos na teoria da titularidade, segundo Nozick, nunca entram em conflito; jamais dois títulos reivindicatórios sobre o mesmo objeto de propriedade podem ser historicamente justos. Em última instância, o Estado não deve ser o dispensador do bem-estar social, mas deve, acima de tudo, defender os direitos dos indivíduos. Num mundo capitalista transformado pela industrialização e pela técnica, o perigo inerente às teses de Rawls, por exemplo, está na mudança do Estado social em Estado-providência, na transformação numa espécie de "sociedade de seguros" em que os cidadãos pagarão o preço da segurança que lhes prometem. Nesse caso, suas liberdades estarão, evidentemente, ameaçadas em nome de sua proteção. A legitimidade política dos arranjos sociais, diz Nozick, fundamenta-se numa exigência de consentimento voluntário.

○ princípio de compensação ou retificação, porém, é bastante questionável. Para começar, Nozick justifica com ele uma atividade redistributiva do Estado, ainda que "por um breve lapso de tempo". O problema é que, dado que os direitos libertarianos não criam uma sociedade bem ordenada, poderia requerer-se que este lapso breve de tempo se prolongasse 
ou que fosse necessário repeti-lo periodicamente. Em segundo lugar, Nozick reconhece que o direito de cada proprietário à sua propriedade inclui a sombra histórica da estipulação lockeana. Por exemplo, se cada um de nós é dono de um poço de água, mas todos, menos um, secam por uma catástrofe natural, a cláusula lockeana cobra com vigor que o proprietário desse único poço em funcionamento já não tenha uso discricionário dele: seu direito foi "superado". A pergunta pertinente é: se a apropriação ou a utilização de recursos, para ser legítima, teve que satisfazer essa condição uma vez, por que não teria que satisfazê-la sempre? No fundo, somente se supusermos - como fazia Locke - que as vantagens da propriedade privada nos levarão ao reino da abundância, a estipulação de Nozick faz algum sentido. Mas vivemos no mundo da abundância, para que nos preocuparmos com os títulos de propriedade?

Retornemos um momento ao primeiro princípio do sistema retributivo de Nozick, o princípio de aquisição apoiado um uma cláusula lockeana enfraquecida. Diz Nozick que a apropriação de um bem é aceitável se realizarmos alguma espécie de compensação às pessoas que vêem piorada sua situação com nosso ato. Poderíamos perguntar-nos: compensá-las como? Materialmente? Quanto vale nossa falta de liberdade no uso da natureza? Quanto vale a falta de liberdade que herdarão nossos descendentes? Além disso, com o que nos vai pagar o apropriador, se não com o mesmo bem que não lhe pertence até que nos compense?

Em todo caso, é necessário reforçar que, em seu princípio de aquisição, Nozick supõe, como Locke, que as pessoas são proprietárias de si mesmas. Ao contrário do filósofo inglês, que acreditava que o mundo era posse comum da humanidade, Nozick parece pensar que o mundo não é de ninguém e está ali pronto para ser apropriado ao primeiro que o reclame. Esta diferença é fundamental, porque é graças a ela que Nozick evita a exigência do consentimento. Ao passar por cima do consentimento na aquisição de propriedade, Nozick está 
repetindo o esquema que utilizou para justificar o Estado mínimo, o qual não requeria que todos os súditos consentissem, mas apenas que fossem compensados por não permanecerem independentes dele. Isto é notável, já que supõe que tanto o apropriador como a agência de segurança atuam de modo tutelar ou paternalista, algo que parece ir na contracorrente da tradição liberal.

Para rematar, o Estado mínimo não é "nosso Estado": é uma agência que reforça nossas interdições morais. Não é necessário que sejamos "cidadãos", mas tão somente súditos que obedecem às leis. Ocorrem-nos então algumas perguntas: quem nos guardará dos possíveis excessos, enganos ou omissões do Estado mínimo? Temos, como na teoria de Locke, direito a resistir? E se a resposta é afirmativa, em razão do que teremos esse direito e com que armas o faremos valer? E ainda sem chegar a esses extremos, nos casos de conflitos entre direitos, dado que a maioria não tem o papel preponderante que possuía nas teses lockeanas, sob que regras se regerá o Estado mínimo e por quê? Em última instância, os argumentos de Nozick não soam como uma forma estilizada das exigências dos neoliberais de acabar com o problema do Estado? Neste sentido, estariam as exigências de demoktesis preenchidas completamente e a democracia eticamente justificada? Mas como falar em democracia quando os seus participantes são reduzidos a meros agentes privados situados numa relação de troca e venda de mercadorias? Privatizar o Estado não seria, portanto, suprimir as próprias relações políticas que os cidadãos mantêm entre si e que servem de proteção às interferências externas, qualquer que seja, estatal ou particular?

Abstract: The present article aims at reconstructing Robert Nozick's central arguments about the extreme positions held by North American libertarians who do not distinguish between Welfare State and Totalitarian State. Despite divergences on a pivotal question, that of the State, there are some affinities between Nozick and this current of thought. Contrary to 
the anarchist theory, the Minimal State is preferable to the state of nature as described by John Locke.

Keywords: Minimal State, property, liberalism, rights, Entitlement Theory.

\section{RFERÊNCIAS}

DUPUY, J.-P. Le sacrifice et l'envie. Paris: Calmann-Lévy, 1992.

HÖFFE, O. L’État et la justice. John Rawls et Robert Nozick. Paris: Vrin, 1988.

LANCEY, A. R. Robert Nozick. Princeton: Princeton University Press, 2001.

NOZICK, R. Anarchy, state, and utopia. New York: Basic Books, 1974.

. Anarquia, estado e utopia. trad. Ruy Jungmann. Rio de Janeiro: Jorge Zahar, 1991.

PARIJS, P. VAN. O que é uma sociedade justa? Trad. C. Ávila de Carvalho. São Paulo: Ática, 1997.

SCMIDTZ, D. (ed.) Robert Nozick. Cambridge: Cambridge University Press, 2002.

TUCK, R. Natural rights theories. Cambridge: Cambridge University Press, 1979.

WOLFF, J. Robert Nozick. Property, justice and the minimal state. Stanford University Press, 1991. 